\title{
Admissions to Canadian hospitals for acute asthma: A prospective, multicentre study
}

\author{
Brian H Rowe MD MSc CCFPEM ${ }^{1}$, Cristina Villa-Roel MD MSc ${ }^{1}$, Riyad B Abu-Laban MD MHSc FRCPC ${ }^{2}$, \\ Rob Stenstrom MD PhD CCFPEM ${ }^{3}$, Duncan Mackey MD CCFPEM ${ }^{4}$, Ian G Stiell MD MSc FRCPC ${ }^{5}$, \\ Sam Campbell MD MB BCh CCFPEM ${ }^{6}$, Bryan Young MD FRCPC ${ }^{7}$
}

\begin{abstract}
BH Rowe, C Villa-Roel, RB Abu-Laban, et al. Admissions to Canadian hospitals for acute asthma: A prospective, multicentre study. Can Respir J 2010;17(1):25-30.
\end{abstract}

BACKGROUND: Asthma exacerbations constitute one of the most common causes of emergency department (ED) attendance in most developed countries. While severe asthma often requires hospitalization, variability in admission practices has been observed.

OBJECTIVE: To describe the factors associated with admission to Canadian hospitals for acute asthma after ED treatment.

METHODS: Subjects 18 to 55 years of age treated for acute asthma in 20 Canadian EDs prospectively underwent a structured ED interview $(\mathrm{n}=695)$ and telephone interview two weeks later.

RESULTS: The median age of the patients was 30 years, and the majority were women $(62.8 \%)$. The admission rate was $13.1 \%$ (95\% CI $10.7 \%$ to $15.8 \%)$. Admitted patients were older, more often receiving oral or inhaled corticosteroids at presentation, and more frequently receiving systemic corticosteroids and magnesium sulphate in the ED. Similar proportions received beta-2 agonists and/or ipratropium bromide within $1 \mathrm{~h}$ of arrival. On multivariable analyses, factors associated with admission included age, previous admission in the past two years, more than eight beta- 2 agonist puffs in the past $24 \mathrm{~h}$, a Canadian Triage and Acuity Score of 1 to 2, a respiratory rate of greater than 22 breaths/min and an oxygen saturation of less than $95 \%$.

CONCLUSION: The admission rate for acute asthma from these Canadian EDs was lower than reported in other North American studies. The present study provides insight into practical factors associated with admission for acute asthma and highlights the importance of history and asthma severity markers on ED decision making. Further efforts to standardize ED management and expedite admission decision-making appear warranted.

Key Words: Admissions; Asthma; Emergency department; Exacerbations; Severity

sthma is a chronic airways condition that affects approxi1 mately $7 \%$ to $10 \%$ of the adult population; the understanding of the key role of inflammation in the pathophysiology of asthma has improved in the past two decades (1). Approximately two million Canadians (2) and 30 million Americans (3) have asthma, with almost $60 \%$ reporting their asthma to be poorly controlled $(2,4)$. Asthma exacerbation is one of the most common causes of emergency department (ED) attendance and represents a significant economic burden in developed countries $(5,6)$. Among patients presenting to the ED for acute asthma treatment in Canada, 51\% report having an unscheduled visit in the previous year and $30 \%$ report having one or more ED visits per year. In the United States, there

\section{Les admissions dans les hôpitaux canadiens en raison d'un asthme aigu : Une étude multicentrique prospective}

HISTORIQUE : Les exacerbations de l'asthme constituent l'une des principales causes de visites au département d'urgence (DU) dans la plupart des pays industrialisés. Bien que l'asthme grave exige souvent une hospitalisation, on a observé une variabilité dans les pratiques d'admission.

OBJECTIF : Décrire les facteurs liés à l'admission dans un hôpital canadien en raison d'un asthme aigu après un traitement au DU.

MÉTHODOLOGIE : Des sujets de 18 à 55 ans traités en raison d'un asthme aigu dans 20 DU canadiens ont passé une entrevue prospective au DU ( $\mathrm{n}=695$ ), suivie d'une entrevue téléphonique deux semaines plus tard.

RÉSULTATS : Les patients avaient un âge médian de 30 ans et étaient majoritairement des femmes (62,8 \%). Le taux d'admission s'élevait à 13,1\% (95\% IC 10,7\% à 15,8\%). Les patients hospitalisés étaient plus âgés, recevaient plus souvent des corticoïdes par voie orale ou en aérosol et on leur donnait plus souvent des corticoïdes et du sulfure de magnésium systémiques au DU. Des proportions similaires recevaient des bêta ${ }_{2}$-agonistes ou du bromure d'ipratropium dans l'heure suivant leur arrivée au DU. D'après les analyses multivariées, les facteurs associés à l'admission incluaient l'âge, l'hospitalisation au cours des deux années précédentes, plus de huit bouffées de bêta 2 -agonistes au cours des 24 heures précédentes, un indice canadien de triage et d'acuité de 1 à 2 , une fréquence respiratoire supérieure à 22 respirations/min et une saturation en oxygène inférieure à $95 \%$.

CONCLUSION : Le taux d'hospitalisation découlant d'un asthme aigu à partir de ces DU canadiens était inférieur à celui déclaré dans d'autres études nord-américaines. La présente étude fournit un aperçu des facteurs pratiques associés à l'hospitalisation découlant d'un asthme aigu et fait ressortir l'importance des antécédents et des marqueurs de gravité de l'asthme dans la prise de décision au DU. D'autres mesures pour normaliser la prise en charge au DU et accélérer la prise de décision au sujet de l'hospitalisation semblent s'imposer.

${ }^{1}$ Department of Emergency Medicine, University of Alberta, Edmonton, Alberta; ${ }^{2}$ Department of Emergency Medicine, Vancouver General Hospital;

${ }^{3}$ Department of Emergency Medicine, St Paul's Hospital, Vancouver, British Columbia; ${ }^{4}$ Department of Emergency Medicine, Lethbridge Regional

Hospital, Lethbridge, Alberta; ${ }^{5}$ Ottawa Health Research Institute, Ottawa, Ontario; ${ }^{6}$ Department of Emergency Medicine, Queen Elizabeth II

Hospital, Halifax, Nova Scotia; ${ }^{7}$ Department of Emergency Medicine, Foothills Medical Centre, Calgary, Alberta. All of the emergency

departments are affiliated with the Canadian Association of Emergency Physicians (CAEP) Research Consortium and are located in Canada

Correspondence: Dr Brian H Rowe, Department of Emergency Medicine, University of Alberta, 1G1.43 Walter C Mackenzie Health Sciences

Centre, 8440-112 Street, Edmonton, Alberta T6G 2B7. Telephone 780-407-6761, fax 780-407-3982, e-mail brian.rowe@ualberta.ca 
Canadian health system, there is a wide spectrum of asthma exacerbations in which decision aids are still needed.

The objective of the present study was to identify factors associated with admission after ED treatment for asthma in Canada.

\section{Design and setting}

\section{METHODS}

The present prospective, observational study enrolled consecutive patients treated for acute asthma in $20 \mathrm{EDs}$ across Canada between June 2004 and December 2005. Twenty-four hour per day recruitment was not possible at any site and coverage depended on research staff availability. All study sites volunteered for participation and were members of the Canadian Association of Emergency Physicians Research Consortium.

\section{Eligibility}

The diagnosis of asthma was made on clinical grounds based on one or more of the following: history of asthma (patient report), response to beta-2 $\left(\beta_{2}\right)$-agonist therapy and worsening symptoms such as wheezing, dyspnea, and cough or chest tightness. Patient management was left to the discretion of the treating emergency physician.

Patients 18 to 55 years of age with diagnosed asthma and no previous diagnosis of chronic obstructive pulmonary disease (COPD) exacerbation, or more than 30 pack-years of smoking exposure, were screened by research staff following referral by emergency physicians. Individuals with pneumonia, cognitive impairment, a language barrier, inability to provide informed consent, any severe condition that could not be stabilized in the ED (eg, status asthmaticus [persistent severe asthma despite therapy] or requirement of intubation), chronic conditions (eg, advanced cancer, severe cardiac disease, HIV) and/or a history of drug/alcohol abuse were not enrolled. Previous enrollment in the study and leaving against medical advice were also exclusions. The study protocol was approved by each site's research ethics board and written informed consent was obtained from all participants.

\section{Data collection}

Following initial management by the treating emergency physician and once the patient's condition was stabilized, a research nurse assessed the patient for eligibility. Patients who met enrollment criteria underwent a structured interview while they were in the ED. The patients' ED course and disposition were obtained after admission or discharge by medical record abstraction using standardized forms. Peak expiratory flow (PEF) was recorded during triage or after the first ED treatment. Telephone interviews were performed two weeks after the ED visit.

\section{Definition of variables}

Admission was defined as an acute visit that resulted in a formal hospitalization. At the time of the study, no site had standardized criteria for admission and the study protocol did not implement such criteria. Sociodemographic factors such as age, sex, ethnicity, educational level, marital status and employment were collected. Smoking status was categorized as never smoked, previous smoker or current smoker. Insurance status was assessed by asking the patient whether they had any type of health insurance that helped them with the cost of prescription medications (ie, medication plan coverage), the percentage of medication costs usually paid by patients and the percentage of patients who reported less medication use than that prescribed by the doctor because of its cost in the previous 12 months. Availability of primary care provider (PCP) status was evaluated by asking 'Do you have a family physician?' PEF was standardized as the percentage of the patient's predicted value according to age, sex, ethnicity and height (11).

On arrival to the study hospitals, the Canadian Triage and Acuity Score (CTAS) was used to determine the priority at which patients required assessment. This five-level scale, which ranges from resuscitation (level 1) to nonurgent (level 5), is the national standard for all ED patients, and has been shown to be reliable and valid (12).

\section{Follow-up}

A two-week follow-up identified physician visits for routine assessment, and urgent unscheduled clinic or ED visits for additional care. Hospitalizations and death were also documented. This information was obtained through family reports or through the patients' PCP when patients could not be contacted.

\section{Statistical analysis}

Data were entered by trained personnel. Descriptive data included proportions, means \pm SDs or medians with interquartile ranges (IQRs), as appropriate. A database for refusals, misses and other exclusions was developed at each site. All analyses were performed using SAS version 9.1 (SAS Institute Inc, USA). First, bivariable analyses for dichotomous and continuous variables were performed by $\chi^{2}$ test, and by $t$ tests or Mann-Whitney tests. Next, factors associated with admission and potential admission predictor variables identified by significance testing at $\mathrm{P}<0.15$ were selected for further analysis. A multivariable logistic regression (MLR) model was developed and a stepwise method used to reduce the list of potential predictors so that only those with significant testing at $\mathrm{P}<0.10$ were included. Finally, multivariable modelling with adjustment for clustering of patients at a physician site was performed using a generalized estimating equation logistic method in SAS. Goodness of fit statistics for the MLR model were determined using the c-index (13). The OR and 95\% CI were corrected to derive a more appropriate estimation of the magnitude of the association (ie, risk ratio [RR]) (14). For the final results presented, a predictor was considered statistically significant at $\mathrm{P}<0.05$ in the generalized estimating equation MLR model.

\section{RESULTS}

\section{Enrollment}

During a span of 18 months, 1591 ED patients were screened for enrollment. Patient volume and recruitment variation across sites resulted in a range of patient enrollment of $1 \%$ to $23 \%$. From the pool of individuals who potentially met eligibility criteria, $370(23 \%)$ were missed by treating emergency physicians (the research nurse was not called) and 116 (7\%) refused to participate. An additional 410 patients were excluded during the screening process because of pneumonia $(32.6 \%)$, a severe condition that could not be stabilized in the ED (10.6\%), or a COPD exacerbation or more than 30 packyears of smoking (6.8\%). From these additional exclusions, $50 \%$ were not enrolled for other reasons such as chronic pathological conditions, history of drug or alcohol abuse, cognitive 


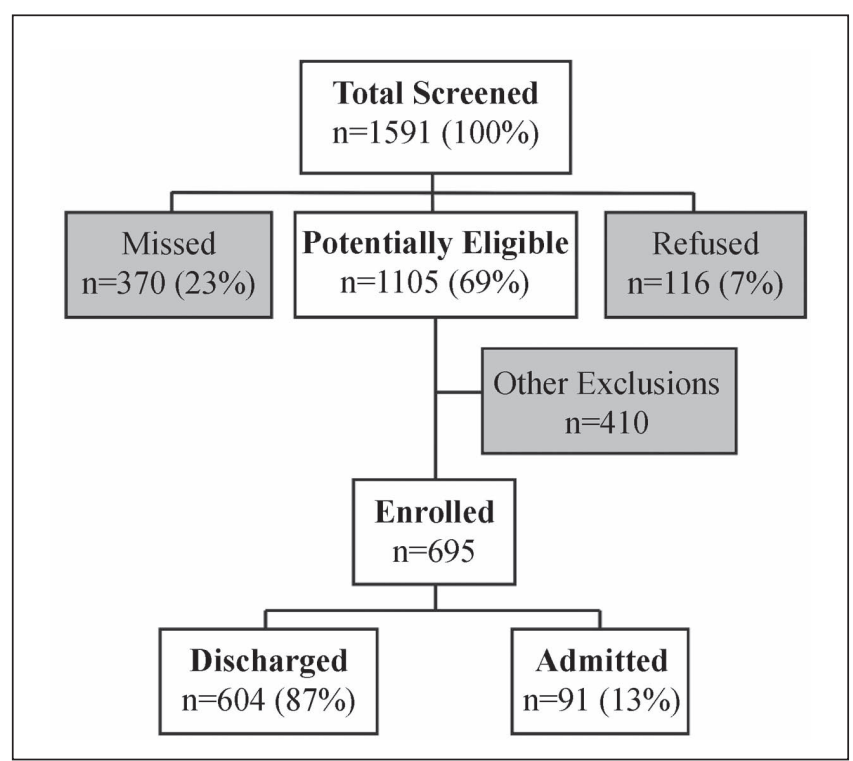

Figure 1) Study patient flow

impairment, previous enrollment in the study and patients who left the ED against medical advice. Therefore, the final study enrollment included 695 patients (44\% of the total screened patients) (Figure 1). Patients not enrolled were slightly older than enrolled patients (33 years versus 30 years; $\mathrm{P}=0.001$ ); however, the groups had a similar sex distribution.

\section{Patient characteristics}

Table 1 summarizes median ages and sex distribution according to admission status. The median age of the patients was 30 years and more patients were women (62.8\%). Most patients were Caucasian (84.2\%), although other ethnicities were represented.

\section{Outcome}

The admission rate was $13.1 \%$ (95\% CI $10.7 \%$ to $15.8 \%$ ). Patients who were admitted were older, had a lower educational level and a greater proportion had previously smoked compared with those who were discharged. No significant differences were observed in sex distribution, medication plan coverage or PCP availability between the admitted and discharged groups.

\section{Asthma history}

Patients who were admitted were more likely to report admissions for asthma during the past two years and to have previously received oral corticosteroids (CS) and other treatments for their asthma.

\section{Severity of asthma presentation}

The CTAS, vital signs and oxygen saturation (with 94\% of the patients on room air) significantly differed between admitted and discharged patients. A higher number of $\beta_{2}$-agonist puffs within $24 \mathrm{~h}$ of the ED visit was reported by admitted patients, and, of these subjects, a lower mean earliest and final PEF and per cent predicted PEF were observed (Table 2).

\section{ED course}

Overall, $85 \%$ of the patients received $\beta_{2}$-agonists, $79 \%$ anticholinergics, $80 \%$ oral CS and 36\% additional asthma therapies
TABLE 1

Characteristics of enrolled patients with acute asthma categorized by admission status

\begin{tabular}{|c|c|c|c|}
\hline \multirow[b]{2}{*}{ Characteristic } & \multicolumn{2}{|c|}{ Patients } & \multirow[b]{2}{*}{$\mathbf{P}$} \\
\hline & $\begin{array}{l}\text { Admitted } \\
(n=91)\end{array}$ & $\begin{array}{l}\text { Discharged } \\
(n=604)\end{array}$ & \\
\hline Age, years (mean \pm SD) & $36.4 \pm 10.2$ & $31.1 \pm 9.9$ & $<0.001$ \\
\hline Female sex & $59(64.8)$ & $379(62.7)$ & 0.701 \\
\hline \multicolumn{4}{|l|}{ Ethnicity } \\
\hline Caucasian & $70(76.9)$ & $515(85.2)$ & 0.032 \\
\hline Aboriginal & - & $17(2.8)$ & - \\
\hline Asian & $5(5.5)$ & $13(2.2)$ & - \\
\hline East Indian & $3(3.3)$ & $17(2.8)$ & - \\
\hline Black & $6(6.6)$ & $18(3)$ & - \\
\hline Other & $7(7.7)$ & $24(4)$ & - \\
\hline High school graduate & $64(70.3)$ & $507(83.9)$ & 0.002 \\
\hline Marital status (married/common law) & $46(50.5)$ & $257(42.5)$ & 0.151 \\
\hline Employment (full-time) & $39(42.8)$ & $283(46.8)$ & 0.476 \\
\hline \multicolumn{4}{|l|}{ Smoking status } \\
\hline Never & $30(32.9)$ & $231(38.2)$ & 0.041 \\
\hline Previous & $36(39.6)$ & $162(26.8)$ & \\
\hline Current & $25(27.5)$ & $211(34.9)$ & \\
\hline Pack-years smoked*, median (IQR) & $8(4-14)$ & $4(1-8)$ & $<0.001$ \\
\hline \multicolumn{4}{|l|}{ Insurance status } \\
\hline Medication plan coverage, $\mathrm{n} / \mathrm{n}(\%)$ & $57 / 73(78.0) 3$ & $329 / 455(72.3)$ & 0.556 \\
\hline $\begin{array}{l}\text { Percentage paid by the patient, } \\
\text { median (IQR) }\end{array}$ & $20(20-28.5)$ & $20(0-20)$ & $<0.001$ \\
\hline Reported less medication use, $\mathrm{n} / \mathrm{n}(\%)$ & $23 / 64(35.9)$ & $119 / 433(27.4)$ & 0.222 \\
\hline Had primary care provider & $75(82.4)$ & $492(81.4)$ & 0.826 \\
\hline \multicolumn{4}{|l|}{ Chronic asthma factors } \\
\hline $\begin{array}{l}\text { Ever taken steroid medicine for } \\
\text { asthma }\end{array}$ & $68(74.7)$ & $358(59.2)$ & 0.005 \\
\hline Ever hospitalized for asthma & $58(63.7)$ & $307(50.8)$ & 0.062 \\
\hline Ever intubated for asthma & $11(12.0)$ & $52(8.6)$ & 0.554 \\
\hline $\begin{array}{l}\text { ED visits in the past } 2 \text { years, } \\
\text { median (IQR) }\end{array}$ & $1(0-3)$ & $1(0-4)$ & 0.116 \\
\hline $\begin{array}{l}\text { Admitted for asthma in the past } \\
2 \text { years }\end{array}$ & $36(39.5)$ & $126(20.8)$ & $<0.001$ \\
\hline $\begin{array}{l}\text { ED usual site for problem asthma } \\
\text { care }\end{array}$ & $56(61.5)$ & $362(59.9)$ & 0.771 \\
\hline $\begin{array}{l}\text { ED usual source of asthma } \\
\text { prescriptions }\end{array}$ & $7(7.6)$ & $60(9.9)$ & 0.499 \\
\hline \multicolumn{4}{|l|}{ Medications at presentation to the ED } \\
\hline Inhaled SABA & $70(76.9)$ & $493(81.6)$ & 0.287 \\
\hline Inhaled CS & $30(32.9)$ & $187(30.9)$ & 0.700 \\
\hline Inhaled LABA & $8(8.7)$ & $23(3.8)$ & 0.032 \\
\hline $\begin{array}{l}\text { Combination agents (inhaled CS + } \\
\text { LABA) }\end{array}$ & $36(39.5)$ & $183(30.2)$ & 0.076 \\
\hline Leukotriene modifier/antagonist & $7(7.6)$ & $44(7.2)$ & 0.889 \\
\hline Oral corticosteroids & $18(19.7)$ & $44(7.2)$ & $<0.001$ \\
\hline Anticholinergics & $9(9.8)$ & $32(5.2)$ & 0.114 \\
\hline Short-acting anticholinergics & $6(6.5)$ & $27(4.4)$ & \\
\hline Long-acting anticholinergics & $3(3.2)$ & $5(0.9)$ & \\
\hline Combined SABA + anticholinergics & $10(10.9)$ & $17(2.8)$ & $<0.001$ \\
\hline Theophylline & $4(5.5)$ & $6(1)$ & 0.011 \\
\hline Antibiotics & $4(5.5)$ & $10(1.6)$ & 0.151 \\
\hline
\end{tabular}

Data presented as $n$ (\%) unless indicated otherwise. *Calculated by multiplying the number of packs per day with the number of years smoked. CS Corticosteroid; ED Emergency department; IQR Interquartile range. $L A B A$ Long-acting beta-2 agonist; SABA Short-acting beta-2 agonist 
TABLE 2

Acute asthma presentation of patients categorized by admission status

\begin{tabular}{|c|c|c|c|}
\hline & \multicolumn{2}{|c|}{ Patients } & \multirow[b]{2}{*}{$\mathbf{P}$} \\
\hline & $\begin{array}{l}\text { Admitted } \\
(n=91)\end{array}$ & $\begin{array}{l}\text { Discharged } \\
(n=604)\end{array}$ & \\
\hline$\overline{\text { CTAS, median (IQR) }}$ & $2(2-3)$ & $3(3-4)$ & $<0.001$ \\
\hline \multicolumn{4}{|l|}{ CTAS, n (\%) } \\
\hline 1,2 & $45(49.5)$ & $116(19.2)$ & - \\
\hline 3 & $39(42.8)$ & $297(49.2)$ & - \\
\hline 4,5 & $4(4.4)$ & $147(24.3)$ & - \\
\hline Not documented & $3(3.3)$ & $44(7.3)$ & - \\
\hline \multicolumn{4}{|l|}{ Duration of symptoms, $\mathrm{n}(\%)$} \\
\hline$\leq 24 \mathrm{~h}$ & $7(7.6)$ & $57(9.4)$ & 0.590 \\
\hline$>24 \mathrm{~h}$ & $83(91.2)$ & $540(89.4)$ & \\
\hline $\begin{array}{l}\text { Inhaled } \beta_{2} \text {-agonist puffs within } 24 \mathrm{~h} \\
\text { of } E D \text {, median (IQR) }\end{array}$ & $10(4-20)$ & $8(1-15)$ & 0.012 \\
\hline $\begin{array}{l}>8 \text { inhaled } \beta_{2} \text {-agonist puffs } \\
\text { within } 24 \mathrm{~h} \text { of ED, } \mathrm{n}(\%)\end{array}$ & $61(67.0)$ & $308(51)$ & 0.003 \\
\hline \multicolumn{4}{|l|}{ Vital signs } \\
\hline Pulse, beats/min & $113 \pm 20.3$ & $99.7 \pm 18.3$ & $<0.001$ \\
\hline Respiratory rate, breaths/min & $27.3 \pm 10.6$ & $22.9 \pm 6.0$ & $<0.001$ \\
\hline $\begin{array}{l}\text { Respiratory rate }>22 \text { breaths } / \mathrm{min}, \\
\mathrm{n}(\%)\end{array}$ & $69(76)$ & $313(52)$ & $<0.001$ \\
\hline $\mathrm{SaO}_{2}, \%$ & $92.4 \pm 6.9$ & $95.9 \pm 3.3$ & $<0.001$ \\
\hline $\mathrm{SaO}_{2}<95 \%, \mathrm{n}(\%)$ & $53(58.9)$ & $171(28.5)$ & $<0.0001$ \\
\hline Temperature, ${ }^{\circ} \mathrm{C}$ & $36.9 \pm 0.8$ & $36.6 \pm 0.7$ & $<0.001$ \\
\hline \multicolumn{4}{|l|}{ Lung function } \\
\hline Earliest PEF, L/min* & $210.5 \pm 77.4$ & $286.0 \pm 111.3$ & $<0.001$ \\
\hline Final PEF, L/min ${ }^{\dagger}$ & $278.3 \pm 153.1$ & $427.6 \pm 183.2$ & $<0.001$ \\
\hline Change in $\mathrm{PEF}^{\ddagger}$ & $59.1 \pm 125.7$ & $164.8 \pm 166.7$ & $<0.001$ \\
\hline Earliest $\%$ predicted $\mathrm{PEF}^{\S}$ & $43.4 \pm 14.9$ & $59.3 \pm 22.6$ & $<0.001$ \\
\hline Final \% predicted PEF『 & $59.1 \pm 36.0$ & $88.9 \pm 37.8$ & $<0.001$ \\
\hline Change in $\%$ predicted $\mathrm{PEF}^{\star *}$ & $13.1 \pm 27.4$ & $34.4 \pm 33.8$ & $<0.001$ \\
\hline
\end{tabular}

Data presented as mean $\pm S D$ unless indicated otherwise. *Data available for 534 patients; ${ }^{\dagger}$ Data available for 630 patients; ${ }^{\ddagger}$ Data available for 498 patients; ${ }^{\S}$ Data available for 518 patients; "Data available for 602 patients; **Data available for 483 patients. $\beta$ Beta; CTAS Canadian Triage and Acuity Score; IQR Interquartile range; ED Emergency department; PEF Peak expiratory flow; $\mathrm{SaO}_{2}$ Oxygen saturation

(most commonly intravenous magnesium). Differences were found in ED treatment according to admission status (Table 3); however, similar proportions received $\beta_{2}$-agonists and/or ipratropium bromide within $1 \mathrm{~h}$ of ED presentation. Systemic CS and magnesium sulphate delivery in the ED was higher for admitted patients.

The median ED length of stay (LOS) was longer for those who were admitted than for those who were discharged $(10.7 \mathrm{~h}$ [IQR $8.2 \mathrm{~h}$ to $23.1 \mathrm{~h}$ ] versus $3.7 \mathrm{~h}$ [IQR $2.6 \mathrm{~h}$ to $5.2 \mathrm{~h}$ ]; $\mathrm{P}<0.0001)$. The median LOS for admitted patients was 3 days (IQR 2 days to 5 days).

Follow-up

Follow-up interviews were completed for 613 (88\%) of the enrolled patients. Overall, $32 \%$ of the patients were seen by a physician as part of routine care within two weeks of the ED visit, and $14 \%$ of the discharged patients and $5 \%$ of the admitted patients had an urgent unscheduled clinic or ED visit for additional care during this period of time, resulting in the admission of $15 \%$ of the previously discharged patients. Two deaths were documented: one admitted patient died in hospital
TABLE 3

Characteristics of emergency department (ED) course categorized by admission status

\begin{tabular}{|c|c|c|c|}
\hline Characteristic & $\begin{array}{l}\text { Admitted } \\
(n=91)\end{array}$ & $\begin{array}{l}\text { Discharged } \\
(n=604)\end{array}$ & $\mathbf{P}$ \\
\hline $\begin{array}{l}\text { Received inhaled } \beta_{2} \text {-agonists in first } \\
\text { hour of arrival }\end{array}$ & $61(67.0)$ & $374(61.9)$ & 0.476 \\
\hline Treatments*, median (IQR) & $2(0-3)$ & $1(0-2)$ & 0.021 \\
\hline $\begin{array}{l}\text { Received inhaled } \beta_{2} \text {-agonists during } \\
\text { ED stay }\end{array}$ & $82(90.1)$ & $511(84.6)$ & 0.336 \\
\hline Treatments*, median (IQR) & $7(4-11)$ & $3(1-4)$ & $<0.001$ \\
\hline $\begin{array}{l}\text { Received any systemic corticosteroid } \\
\text { treatment }\end{array}$ & $86(94.5)$ & $468(77.5)$ & $<0.001$ \\
\hline $\begin{array}{l}\text { Received inhaled anticholinergics in } \\
\text { first hour of arrival }\end{array}$ & $54(59.3)$ & $340(56.2)$ & 0.523 \\
\hline Treatments*, median (IQR) & $1(0-2)$ & $1(0-2)$ & 0.916 \\
\hline $\begin{array}{l}\text { Received inhaled anticholinergics } \\
\text { during ED stay }\end{array}$ & $80(87.9)$ & $461(76.3)$ & 0.451 \\
\hline Treatments*, median (IQR) & $4(2-6)$ & $2(1-3)$ & $<0.001$ \\
\hline $\mathrm{MgSO}_{4}$ medication in the ED & $20(22)$ & $12(2)$ & $<0.001$ \\
\hline
\end{tabular}

Data presented as $n$ (\%) unless indicated otherwise. *Each nebulizer treatment was counted as equivalent to six 'puffs' from a metered-dose inhaler. $\beta$ Beta; IQR interquartile range; $\mathrm{MgSO}_{4}$ Magnesium sulphate (intravenous) $^{2}$

\section{TABLE 4}

Multivariable modelling predictors of admission following emergency department (ED) treatment

\begin{tabular}{llllr}
\hline Domain & Factors & RR & 95\% Cl & P \\
\hline Demographic & Age, per 10 years & 1.5 & $(1.2-1.9)$ & $<0.001$ \\
& $\begin{array}{l}\text { Female sex } \\
\text { Asthma history }\end{array}$ & 1 & $(0.6-1.6)$ & 0.972 \\
& $\begin{array}{l}\text { Previous admissions in past } \\
\text { 2 years }\end{array}$ & 1.8 & $(1.1-2.7)$ & 0.011 \\
$\begin{array}{l}\text { Severity at } \\
\text { presentation }\end{array}$ & $\begin{array}{l}\text { CTAS of 1 or 2 at ED } \\
\text { presentation }\end{array}$ & 2.3 & $(1.5-3.5)$ & $<0.001$ \\
& $\begin{array}{l}\text { More than 8 } \beta_{2} \text {-agonist puffs } \\
\text { in past 24 h }\end{array}$ & 1.7 & $(1.1-2.5)$ & 0.030 \\
& $\begin{array}{l}\text { Respiratory rate }>22 \\
\text { breaths/min }\end{array}$ & 1.9 & $(1.2-3.0)$ & 0.007 \\
& Oxygen saturation <95\% & 2.2 & $(1.4-3.2)$ & $<0.001$ \\
\hline
\end{tabular}

$\beta$ Beta; CTAS Canadian Triage Acuity Score; RR Risk ratio

(due to respiratory complications) and one discharged patient died following an illness unrelated to his asthma.

Factors associated with admission

Significant factors associated with admission were age (RR 1.5 per 10 years; $95 \%$ CI 1.2 to 1.9 ); previous admission in the past two years (RR 1.8; 95\% CI 1.1 to 2.7 ); more than eight $\beta_{2}$-agonist puffs in the past $24 \mathrm{~h}$ (RR 1.7 ; $95 \%$ CI 1.1 to 2.5 ); CTAS of 1 or 2 (RR 2.3; 95\% CI 1.5 to 3.5); respiratory rate greater than 22 breaths/min (RR 1.9; 95\% CI 1.2 to 3 ) and oxygen saturation less than $95 \%$ (RR 2.2; 95\% CI 1.4 to 3.2) (Table 4). No interactions were retained in the final MLR model; the c-index goodness of fit was $80 \%$.

\section{DISCUSSION}

The present multicentre, prospective study was, to our knowledge, the first to examine factors associated with admission to hospital for patients presenting to Canadian EDs with exacerbations of asthma. The results can be generalized to patients with acute asthma who are not in extremis and have no acute complication (eg, pneumonia). Other studies have included patients with such 
conditions (10). Because most clinicians agree these patients often require hospitalization and would likely treat them more aggressively, we elected to exclude these patients from our study. Our results provide emergency physicians with practical criteria that could be used when determining the need for admission in patients for whom extremely severe asthma presentations and/or associated comorbidities do not influence this decision. Specifically, our results indicate that older patients with previous admissions for asthma in the past two years, reporting the need for more than eight $\beta_{2}$-agonist puffs during the previous $24 \mathrm{~h}$ and classified as CTAS 1 or 2 , with a respiratory rate of greater than 22 breaths/min and oxygen saturation of less than 95\% at ED presentation, should be carefully assessed and, perhaps, admitted.

A lower proportion of patients required admission compared with reports from other North American centres (13.1\% versus $20 \%$, respectively) and a higher proportion of patients was excluded ( $56 \%$ versus $26 \%$, respectively). These differences could be explained by the specific group of patients who were considered in the present study. It is also important to note that admissions varied among hospitals, possibly reflecting referral patterns, emergency physicians' preference, bed availability and a lack of evidence-based guidance.

Consistent with previous research, several sociodemographic differences between admitted and discharged patients were identified. Interestingly, despite clear chronic markers of instability such as the proportion of admissions for asthma in the past two years, not all patients were receiving anti-inflammatory therapy before their ED presentation. One study (15) comparing American and Canadian ED visits found more Canadian patients used inhaled CS agents in the four weeks before the ED visit and that these patients were less likely to have severe presentations and be admitted. In Canada, where health coverage is universal, the delivery of preventive medications should be higher. This practice variation may explain why control is still elusive for many with asthma, and may be partially responsible for the observed severity and frequency differences at ED presentation.

Of the patients who where admitted, 51\% arrived with lifethreatening conditions and were stabilized in the ED. Low initial triage and acuity scores (predominantly CTAS $=2$ ) and the necessity of more than eight $\beta_{2}$-agonist puffs used $24 \mathrm{~h}$ before the ED visit, were strongly associated with hospitalization after multivariable modelling and represent practical information that could be used in admission decision making. While the CTAS is not universal, many international scales use a similar five-level classification and likely perform similarly. Further research from other countries may enlighten this particular discussion.

In contrast to previous studies, PEF and per cent predicted PEF values were not retained in the final model, probably because their effect was reflected by other physiological parameters (eg, respiratory rate). Another possible explanation could be that several patients did not have airway obstruction measurements taken on arrival; consequently, 'earliest' values may have been biased and per cent change from baseline over time could not be determined.

While in the ED, more timely and aggressive treatment was given to the sickest asthmatic patients; however, nearly onethird of all patients (including those who required admission) did not receive bronchodilator treatment within $1 \mathrm{~h}$ of their presentation. The ED LOS in the admitted group was prolonged (median approximately $11 \mathrm{~h}$ ). This reflects the considerable period of time that Canadian patients spend in the ED receiving acute asthma care and could be related to bed shortage and EDs being overcrowded with admitted inpatients (15). The median hospital LOS was three days, with 20\% being discharged the day after being admitted. Overall, such gaps in acute treatment and delays in care could be related to unnecessary admissions and underscore the fact that asthma decision-making in these EDs is not timely or evidence based. Moreover, the low proportion of patients seen by a physician after their exacerbation (32\%) suggests deficiencies in primary health care provision and may be an important issue for patients with poorly controlled asthma. Recently, a practical set of factors associated with relapse has been identified to assist clinicians with decision making (16).

The present study has some potential limitations. First, there was a variation in the percentage of patients enrolled across the study sites due to limited staff availability; however, this should not have influenced the results because the study sites were administratively similar and standardized recruitment strategies were used. Second, our sample was restricted to a specific group of patients presenting with exacerbations, which influences generalizability; however, this allowed us to analyze a more homogeneous population and provides novelty over previously published data. Moreover, the proportions of excluded patients and their reasons were reported. We cannot estimate whether refusals, missed or excluded patients would have been more or less likely to be admitted because of the lack of a complete sociodemographic and clinical characterization (potential selection bias). Third, the diagnosis of asthma based on a physician's criterion may seem arbitrary; nevertheless, it has been widely used in many ED-based studies $(9,10)$ and its validity has been found to be acceptable (17). Recent concern regarding asthma misdiagnosis in Canadian clinic-based practices likely applies less so here (18). Fourth, admission criteria were not standardized among participating centres and some factors not recorded in the study forms could have influenced disposition status. Fifth, some measurements were not completely obtained (eg, PEF and per cent predicted PEF), which can, in part, bias the results; however, it is recognized that their recording is variable in Canadian ED asthma management. Sixth, study sites were mostly urban teaching hospitals; consequently, site physicians may have been more familiar with consensus; therefore, our results may not be generalizable to all Canadian or North American EDs. In an effort to enhance generalizability, however, we included a number of community hospitals. Seventh, it is conceivable that some of the significant univariable differences we found arose by chance. In the final model, variables were adjusted for potential differences in their distributions. Eighth, the distinction between association and causation among factors is difficult to assess given the study design. Finally, study patients did not receive a standard ED management protocol at each site. Admission status may have been influenced by situations in which treatment was suboptimal.

Notwithstanding the above limitations, the results of our study suggest that emergency physicians in Canadian EDs are practicing in accordance with evidence-based guidelines for acute asthma $(7,8,19)$. Based on the median age of the study population, $50 \%$ of the patients fulfilling three of the major 
criteria associated with admission (CTAS 1 or 2, respiratory rate greater than 22 breaths/min and oxygen saturation less than 95\%) were admitted to these Canadian EDs. While these and other factors identified by our study require further validation, they suggest that individuals with certain asthma features should be monitored more closely, and that they could benefit from interventions such as the implementation of care maps, aggressive treatment and early admission decisions while in the ED. We identified some areas of concern that may represent nonadherence on the part of patients, lack of access to PCPs (20), and a failure by PCPs to follow patients after an acute exacerbation or a combination of all of the above. Finally, one alarming feature is that, despite clear severity markers, not all patients were receiving anti-inflammatory therapy before ED presentation.

Most importantly, our study provides further and practical understanding of the factors associated with hospitalization for patients with acute asthma who present to Canadian EDs, and confirms the importance of history, asthma severity markers and concurrent anti-inflammatory treatments on admission decisions in the ED. Future studies should focus on interventions to expedite admission decision making, improve linkage of patients with a PCP following ED visits and admission, and prevention of future asthma exacerbations in high-risk patients.

ACKNOWLEDGEMENTS: The authors thank GlaxoSmithKline, who provided an investigator-initiated, unrestricted, research grant to the Canadian Association of Emergency Physicians (CAEP) Research Consortium to fund this study; CAEP for their support of the Research Consortium and this project; and the Department of Emergency Medicine Research Group (EMeRG) at the University of Alberta, for their support of this project. The research team thanks Sandra Blitz (MSc) and William Midodzi (PhD, PStat Epidemiology, Coordinating and Research Centre) for their support with the statistical analyses, Diane Milette for her secretarial support and the following site Principal Investigators for their assistance (according to recruitment numbers): Duncan Mackey (Lethbridge, Alberta), Brian Rowe (Edmonton, Alberta), Eddy Lang (Montreal, Quebec), Alan Walker (Edmonton, Alberta), Scott Ross (St Albert, Alberta), Marco Sivilotti (Kingston, Ontario), Bryan Young (Calgary, Alberta), Bjug Borgandvaag (Toronto, Ontario), Ian Stiell (Ottawa, Ontario), Rob Stenstrom (Vancouver, British Columbia), Riyad Abu-Laban (Vancouver, British Columbia), Sam Campbell (Halifax, Nova Scotia) and Andrew Worster (Hamilton, Ontario). The authors express their gratitude to the following research staff for their assistance in site coordination (according to order of recruitment): Marlene Myles, Leslie Tyler (CAEP Research Coordinator), Chris Tselios, Cristina Ciolofan, Debbie Boyko, Michelle Pachal, Kathy Bowes, Rod Iwanow, Renee Vilneff, Michelle Loftus, Christine Leclair, Courtney Barker, Jan Buchanan, Daphne Murray, Megan Brophy, Kim Elliot and Christina Brean.

\section{REFERENCES}

1. O'Byrne PM. Airway inflammation and the pathogenesis of asthma. Can Respir J 1994;1:189-95.

2. Chapman KR, Ernst P, Grenville A, Dewland P, Zimmerman S. Control of asthma in Canada: Failure to achieve guideline targets. Can Respir J 2001;8:35A-40A. (Abst)

3. American Lung Association. Trends in asthma morbidity and mortality. 2007.

4. Fitzgerald JM, Boulet L-P, McIvor RA, Zimmerman S, Chapman KR. Asthma control in Canada remains suboptimal: The reality of asthma control (TRAC) study. Can Respir J 2006;13:253-9.

5. Weiss KB, Sullivan SD, Lyttle CS. Trends in the cost of illness for asthma in the United States, 1985-1994. J Allergy Clin Immun 2000;106:493-9.

6. Weiss KB, Sullivan SD. The health economics of asthma and rhinitis. I. Assessing the economic impact. J Allergy Clin Immun 2001;107:3-8.

7. Beveridge RC, Grunfeld AF, Hodder RV, Verbeek PR; CAEP CTS Asthma Advisory Committee. Guidelines for the emergency management of asthma in adults. CMAJ 1996;155:25-37.

8. Boulet L-P, Becker A, Berube D, Beveridge RC, Ernst P; on behalf of the Canadian Asthma Consensus Group. Canadian Asthma Consensus Report, 1999. CMAJ 1999;161:S1-S61.

9. Lougheed MD, Garvey N, Chapman KR, et al. The Ontario Asthma Regional Variation Study: Emergency department visit rates and the relation to hospitalization rates. Chest 2006;129:909-17.

10. Weber EJ, Silverman RA, Callaham ML, et al. A prospective multicenter study of factors associated with hospital admission among adults with acute asthma. Am J Med 2002;113:371-8.

11. Hankinson JL, Odencrantz JR, Fedan KB. Spirometric reference values from a sample of the general US population. Am J Respir Crit Care Med 1999;159:179-87.

12. Beveridge R. The Canadian Triage and Acuity Scale: A new and critical element in health care reform. J Emerg Med 1998;16:507-11.

13. Lemeshow S, Hosmer DW Jr. A review of goodness of fit statistics for use in the development of logistic regression models. Am J Epidemiol 1982;115:92-106.

14. Zhang J, Yu KF. What's the relative risk? A method of correcting the odds ratio in cohort studies of common outcomes. JAMA 1998;280:1690-1.

15. Rowe BH, Bota GW, Clark S, Camargo CA Jr; for the MARC Investigators. Comparison of Canadian versus US emergency department visits for acute asthma. Can Respir J 2007;14:331-7.

16. Rowe BH, Villa-Roel C, Sivilottii M, et al. Relapse following emergency department discharge for acute asthma: A prospective multi-center study. Acad Emerg Med 2008;15:709-17.

17. Stieb DM, Beveridge RC, Rowe BH, Walter SD, Judek S. Assessing diagnostic classification in an emergency department: Implications for daily time series studies of air pollution. Am J Epidemiol 1998;148:666-70.

18. Aaron SD, Vandemheen KL, Boulet LP, et al. Overdiagnosis of asthma in obese and nonobese adults. CMAJ 2008;179:1121-31.

19. National Asthma Education Prevention Program (NAEPP). Expert Panel Report 3: Guidelines for the Diagnosis and Management of Asthma (EPR-3 2007) NIH Publication. Bethesda, Maryland, USA: Department of Health and Human Services; National Institutes of Health; National Heart, Lung, and Blood Institute; National Asthma Education and Prevention Program. 2007.

20. Han A, Ospina M, Blitz S, Strome T, Rowe BH. Patients presenting to the emergency department: Use of other health care services and reasons for presentation. Can J Emerg Med 2007;9:428-34. 


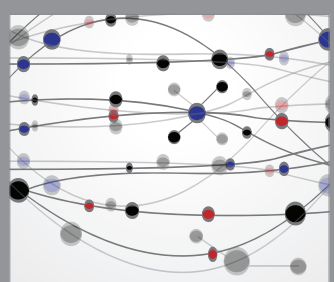

The Scientific World Journal
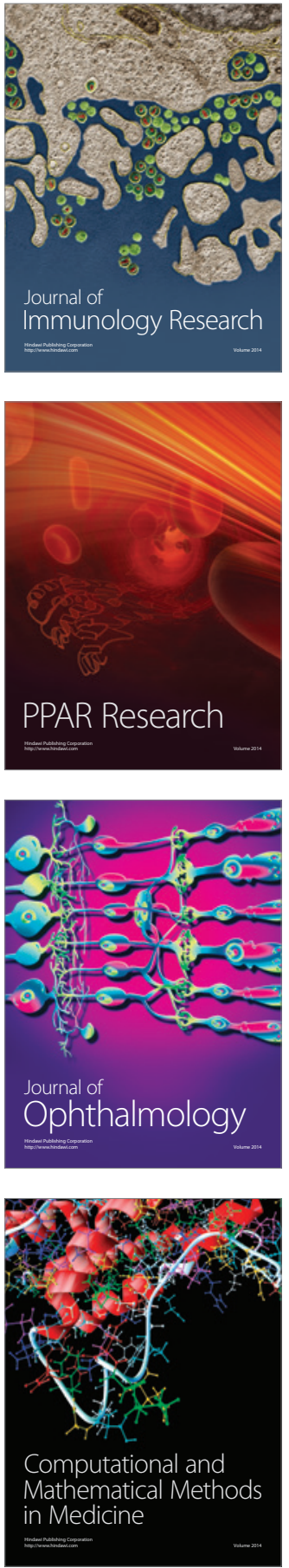

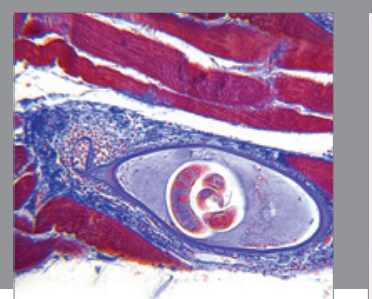

Gastroenterology Research and Practice

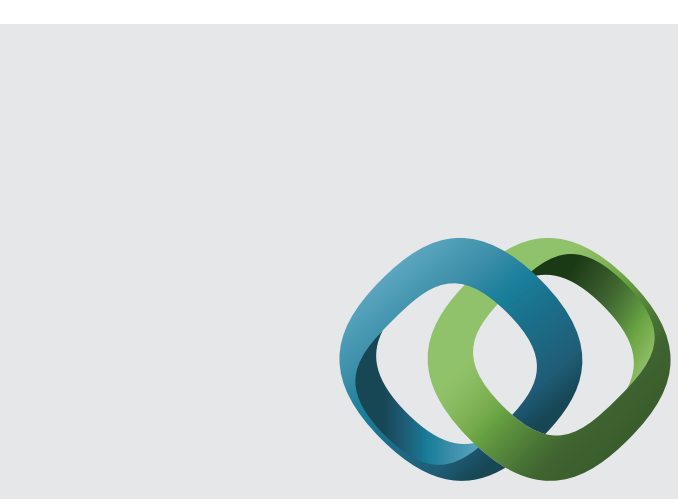

\section{Hindawi}

Submit your manuscripts at

http://www.hindawi.com
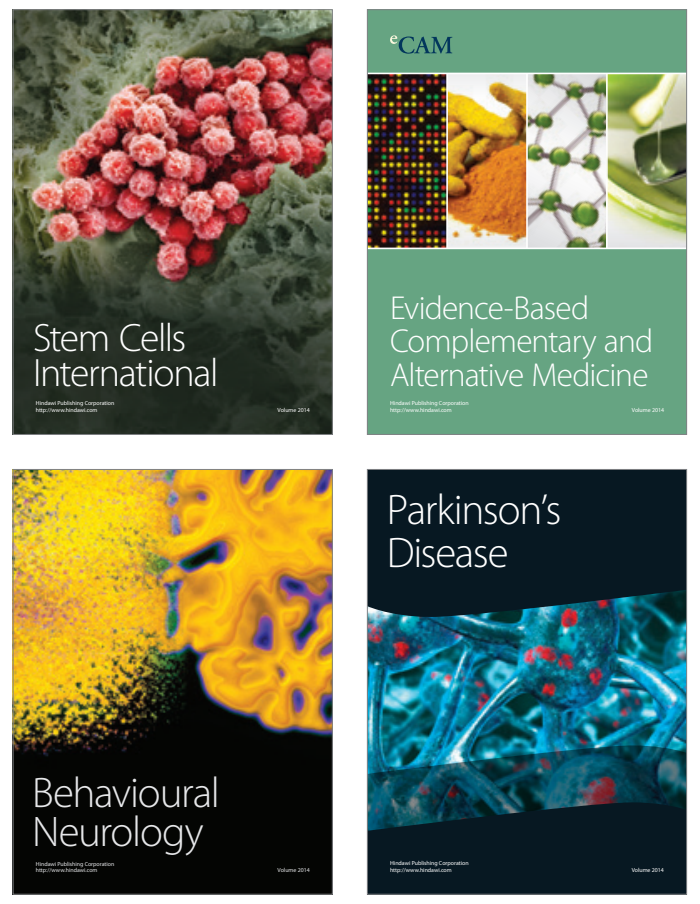
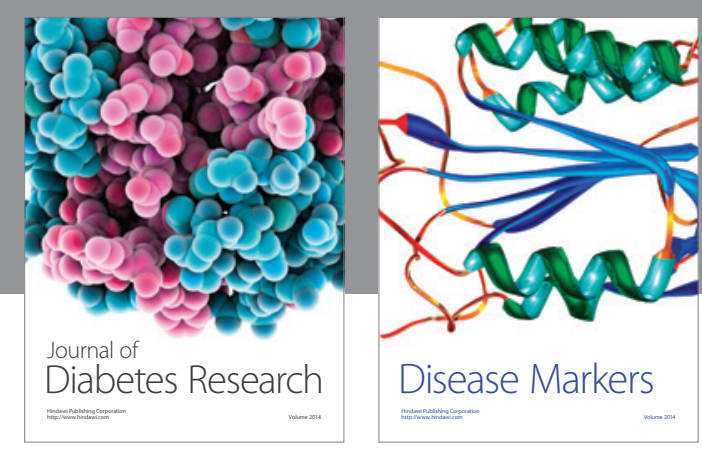

Disease Markers
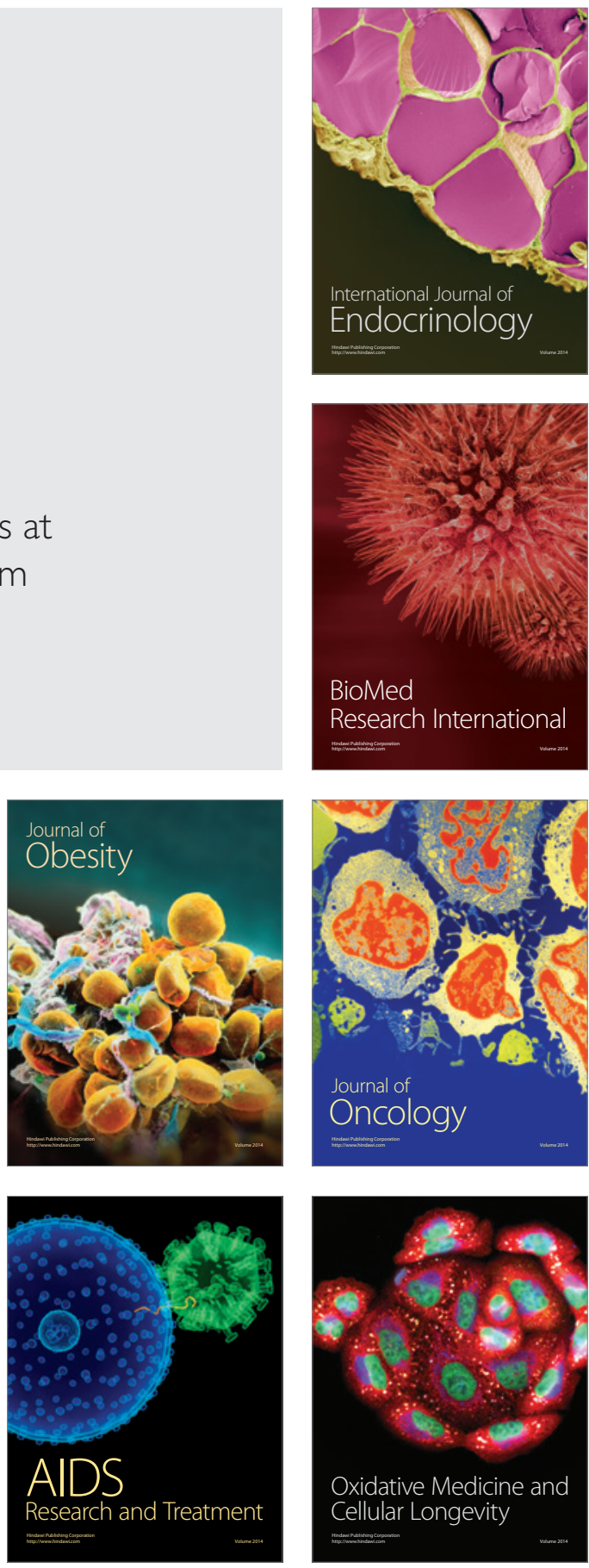